PONCE, Ana; PIEDRAHITA, Pedro; VILLAGÓMEZ, Richard “Toma de decisiones y

responsabilidad penal frente al lavado de activos en Ecuador".

Polít. Crim. Vol. 14, No 28 (Diciembre 2019), Art. 9, pp. 365-384.

[http://politcrim.com/wp-content/uploads/2019/12/Vol14N28A9.pdf]

\title{
Toma de decisiones y responsabilidad penal frente al lavado de activos en Ecuador
}

\section{Decision making and criminal responsibility regarding money laundering in Ecuador}

\author{
Ana Lucía Ponce Andrade \\ Magister en Gestión Empresarial, Universidad Regional Autónoma de los Andes; Doctoranda en \\ Administración Estratégica de Empresas, CENTRUM Pontificia Universidad Católica de Perú. \\ Profesora del Instituto de Altos Estudios Nacionales, Centro de Gobierno y Administración \\ Pública. \\ ana.ponce@iaen.edu.ec
}

Pedro Piedrahita Bustamante

Doctor Cum Laude en Derecho Internacional, Universidad Alfonso X el Sabio de España; Magíster en Seguridad y Defensa, Escuela Superior de Guerra de Bogotá y Politólogo, Universidad Pontificia Bolivariana.

Profesor investigador de la Universidad de Medellín, Facultad de Ciencias Sociales y Humanas; miembro del grupo de investigación en Conflicto y Paz de la misma universidad.

ppiedrahita@udem.edu.co

Richard Ítalo Villagómez Cabezas

Magister en Derecho Procesal Penal, Universidad Andina Simón Bolívar; Doctorando en

Derecho, Pontificia Universidad Católica de Perú.

Conjuez de la Corte Nacional de Justicia del Ecuador.

richard.villagomez@cortenacional.gob.ec

\section{Resumen}

El lavado de activos es un fenómeno delictual transnacional que incide en los países dentro de una economía globalizada. En Ecuador, con la entrada en vigencia del Código Orgánico Integral (COIP) de 2014 se sanciona con mayor severidad esta conducta y se incorpora, por primera vez, dentro de la participación penal a las personas jurídicas. En este contexto, empleando la metodología cualitativa y el método del estudio de caso, el artículo busca establecer la toma de la decisión delictual a partir del Análisis Económico del Derecho (AED) de Becker, especialmente la relación costo-beneficio vista desde la perspectiva del agente (persona natural-jurídica). Se evidencia que la pena impuesta a persona natural puede generar un costo para el Estado, mientras que a la persona jurídica es una afectación a la organización y, por extensión, al circuito económico del país.

Palabras Clave: lavado de activos, costo-beneficio, impunidad-beneficio, Análisis Económico del Derecho, Crimen Organizado Transnacional. 


\begin{abstract}
Money laundering is a transnational criminal phenomenon that affects countries within a globalized economy. In Ecuador, when the Integral Organic Code (COIP) comes into force in 2014, this conduct is sanctioned more severely and, for the first time, legal persons are included in criminal activities. In this context, by using a qualitative methodology and the case study method, this paper seeks to determine the decision of criminal decision on the basis of Becker's Economic Analysis of Law (AED), especially the cost-benefit ratio seen from the perspective of the agent (natural-legal person). The conclusion shows that the penalty imposed on a natural person can generate a cost for the State, whereas for a legal person it entails an affectation on the organization, as well as on the economic circuit of the country.
\end{abstract}

Keywords: money laundering, cost-benefit, impunity-benefit, Economic Analysis of Law, Transnational Organized Crime.

Lo que te echó todo a perder fue la conducta del señor Tchebarof, consejero y hombre de negocios [...]. El hombre honrado y sensible se entrega fácilmente a las confidencias, y el hombre de negocios las recoge para aprovecharse. En una palabra, ella endosó el pagaré a Tchebarof, y éste no vaciló en exigir el pago. Cuando me enteré de todo esto, me propuse, obedeciendo a la voz de mí conciencia, arreglar el asunto un poco a mi modo, pero, entre tanto, se estableció entre Pachenka y yo una corriente de buena armonía, y he puesto fin al asunto atacándolo en sus raíces, por decirlo así. Hemos hecho venir a Tchebarof, le hemos tapado la boca con una pieza de diez rublos y él nos ha devuelto el pagaré. Aquí lo tienes; tengo el honor de devolvértelo. Ahora solamente eres deudor de palabra. Tómalo. Fiódor Dostoyevski - Crimen y Castigo.

\title{
Introducción
}

En 1968 el economista estadounidense Gary Becker planteaba esta pregunta: ¿es posible tomar la decisión de delinquir minimizando los costos de ejercer esta actividad al tiempo que se maximizan sus beneficios? ${ }^{1}$ Becker observaba en la época un alarmante incremento en los costos generados por la economía criminal, a pesar de la maximización del sistema penal, manifestado, a su vez, en un aumento del costo social para detener el delito. Trayendo la experiencia de Becker a la actualidad, durante el período 2005-2014, los flujos financieros provenientes de las economías en desarrollo producto de actividades ilícitas aumentaron de 2 a 3.5 trillones de dólares. ${ }^{2}$ Cifra que contrasta con los recursos que han empleado los Estados durante los últimos años para controlar este delito.

El concepto del lavado de activos surgió en la década de 1920 en la ciudad de Chicago, Estados Unidos, luego de que las mafias locales compraran una serie de lavanderías automáticas que funcionaban con monedas; al final de cada jornada, al producido se le agregaba dinero "negro"

\footnotetext{
${ }^{1}$ BECKER, Gary, "Crime and Punishment: An Economic Approach”, en: BECKER, Gary; LANDES, William, Essays in the Economics of Crime and Punishment, Cambridge: NBER, 1974, pp. 1-54, pp. 1-2.

${ }^{2}$ SPANJERS, Joseph; SALOMON, Matthew, Illicit Financial Flows to and from Developing Countries: 2005-2014, Washington: Global Financial Integrity, 2017, p. VII.
} 


\section{Polít. Crim. Vol. 14, No 28 (Diciembre 2019), Art. 9, pp. 365-384. [http://politcrim.com/wp-content/uploads/2019/12/Vol14N28A9.pdf]}

para presentarlo como ganancia de las máquinas. ${ }^{3}$ En este sentido, se hace evidente que las actividades del crimen organizado generan unos réditos que no pueden justificarse debidamente, lo que lleva a los delincuentes a buscar mecanismos para ocultar los bienes ilícitos dándoles una apariencia de legalidad. ${ }^{4}$ Bajo este orden de ideas, se entiende el lavado de activos como un "proceso delictivo de ocultamiento de activos o de recursos provenientes de actividades ilegales y los subsiguientes actos de simulación para darles apariencia de legalidad y ocultar su origen". 5

A nivel del derecho internacional, se incluyó por primera vez el lavado de activos en la Convención de las Naciones Unidas contra el tráfico ilícito de estupefacientes y sustancias sicotrópicas de 1988. En el artículo tercero de la Convención se estableció la obligación a los Estados parte de tipificar y sancionar este delito. No obstante, de la mano de la evolución de las formas del crimen, se fue ampliando el espectro a otras modalidades de combinación de todas las formas de criminalidad global. ${ }^{6}$ Para 1989 fue constituido por parte de la Organización para la Cooperación y el Desarrollo Económico (OCDE) el Grupo de Acción Financiera Internacional (GAFI), cuyo objetivo es fijar estándares para promover la implementación de normas de todo tipo para combatir el lavado de activos y todas aquellas amenazas contra el sistema financiero internacional. El GAFI entiende que lavar o blanquear activos es un proceso que tiene por objetivo "disfrazar" los réditos del delito y mover su valor a través de transacciones comerciales que buscan legitimar el origen ilícito y se compone de tres fases: colocación, ocultación e integración. $^{7}$

En Ecuador, según la Fiscalía General del Estado (FGE), el número de casos de lavado de activos incrementó de 28 entre agosto y septiembre de 2014, a 69 durante el 2015, y 51 casos entre enero y julio de $2016 .{ }^{8}$ Frente a este fenómeno corresponde indagar a fondo los motivos por los cuales más empresas se instrumentalizan para concretar esta actividad delictiva. El presente artículo pone a prueba los preceptos de la "teoría de juegos" en la toma de decisión de los representantes de una empresa que decide (o no) lavar activos. Luego, se acude a la "teoría económica del crimen" ${ }^{10}$ para analizar un caso resuelto en la Corte Nacional de Justicia de Ecuador. Al final, se sopesan los planteamientos de ambas teorías para proponer la elección más viable, de acuerdo con los intereses económicos y jurídicos de la empresa.

\footnotetext{
${ }^{3}$ CASTELLS, Manuel, La Era de la Información: economía sociedad y cultura. Vol III: Fin del Milenio, México: Siglo XII Editores, 2006, p. 212.

${ }^{4}$ SINTURA, Francisco; MARTÍNEZ, Wilson; QUINTANA, Fernando, Sistemas de prevención de lavado de activos y financiación del terrorismo, Bogotá: Legis, 2014, pp. XXI - XXXII.

${ }_{5}^{5}$ SINTURA / MARTÍNEZ / QUINTANA, Sistemas de prevención, cit. nota ${ }^{\circ}$ 4, pp. 1-2.

${ }^{6}$ PIEDRAHITA, Pedro, "Las redes del crimen global y su impacto en Colombia", Analecta Política, vol. 4 , n 6 (2014), pp. 121-141, p. 128.

${ }^{7}$ FINANCIAL ACTION TASK FORCE, “Money Laundering. Financial Action Task Force”, [En línea] FATFGAFI, (s.f.) [Citado el: 15 de Enero de 2018.] Disponible en: https://www.fatf-gafi.org/faq/moneylaundering.

${ }^{8}$ FLACSO, "Las cifras de lavado de activos", Perfil Criminológico, n 14 (2015), pp. 1-16, p. 15.

${ }^{9}$ DIXIT, Avinash; NALEBUFF, Barry, El arte de la estrategia: la teoría de juegos, Barcelona: Antoni Bosch, 2010, p. 1 .

${ }^{10}$ BECKER, "Crime", cit. nota ${ }^{\circ} 1$.
} 


\section{La Teoría de Juegos y la Elección Racional en la toma de decisión}

En la vida cotidiana, las personas se enfrentan a situaciones en las que tienen que elegir: ¿Qué ropa usar hoy?, ¿será conveniente llevar botas o preferiblemente unos zapatos de charol?, ¿qué comer en el desayuno?, ¿en qué nos vamos a movilizar para llegar al lugar de trabajo?, ¿tomaremos taxi, nos iremos en bus, nos aventuramos a ir en auto propio a pesar del estrés del tránsito de la ciudad? Un sin número de decisiones, desde que se despiertan hasta que duermen, con preguntas de diversa índole en diversos contextos, se enfrentan a situaciones en las que es necesario elegir. Dicha elección está determinada por diversos factores como: gustos, preferencias y conveniencias.

En la vida económica, las empresas también se enfrentan a dilemas diarios que implican tomar decisiones acertadas para su funcionamiento. El cálculo de estas decisiones, en algunos casos, involucra procesos como la identificación de problemas, ponderación o asignación de pesos, el desarrollo, evaluación, selección e implantación de alternativas. ${ }^{11}$ Para la toma de decisiones, las empresas tienen en cuenta aspectos variados, como la relación costo-beneficio, el cálculo de oportunidades, la proyección de mercados, entre otros. La decisión muchas veces se toma considerando la situación interna; pero, sobre todo, la situación de las otras empresas con las que comparte la posición de mercado. La teoría de juegos es una rama de la economía que combina: cálculo matemático y administración empresarial para la toma de decisiones. Una de sus consideraciones evalúa la posición de los agentes que intervienen en una situación dada, de ahí su analogía con el juego: "la lección fundamental de la teoría es que hay que ponerse en el lugar del otro jugador". ${ }^{2}$

Esta teoría tiene su origen histórico en el trabajo paradigmático de Neumann y Morgenstern, Theory of Games and Economic Behavior, ${ }^{13}$ en que se combinan los fundamentos de la matemática pura y la física matemática para explicar los problemas típicos del comportamiento económico. ${ }^{14}$ A pesar de su analogía con los juegos, el asunto se trata de estrategia; por tanto, su foco de análisis recae sobre los conflictos:

"Entre unos oponentes que piensan y que pueden ser capaces de engañar al otro [...] podría pensarse que se trata de una especialidad de la Psicología, en vez de serlo de las Matemáticas. Sin embargo, no lo es, ya que se supone que los jugadores son totalmente racionales, y ello permite un análisis preciso de las situaciones. Así pues, puede afirmarse que la Teoría de Juegos es una rama de la lógica matemática más rigurosa, y subyace a los conflictos reales entre los seres humanos, aunque éstos no sean siempre racionales en sus decisiones". ${ }^{15}$

\footnotetext{
${ }^{11}$ ROBBINS, Stephen; JUDGE, Timothy, Organizational behavior, Boston: Pearsons, 2013, pp. 6-9.

${ }^{12}$ DIXIT / NALEBUFF, El arte, cit. nota n ${ }^{\circ}$ 9, p. 25.

${ }^{13}$ NEUMANN, John; MORGENSTERN Oskar, Theory of Games and Economic Behavior, Princeton: Princeton University Press, 1944, p. 43.

${ }^{14}$ GASTALDI, Carlota; URREA, Marcel; FERNÁNDEZ-DE CÓRDOBA, Pedro, "Teoría de la Decisión: contribuciones de von Neumann”, Divulgaciones Matemáticas, vol. 6, nº 1 (1998), pp. 37-42, p. 38.

${ }^{15}$ GASTALDI / URREA / FERNÁNDEZ-DE CÓRDOBA, "Teoría”, cit. nota n 13, p. 39.
} 


\title{
Polít. Crim. Vol. 14, No 28 (Diciembre 2019), Art. 9, pp. 365-384. [http://politcrim.com/wp-content/uploads/2019/12/Vol14N28A9.pdf]
}

En relación con este enfoque existen otros trabajos que generan nuevos marcos analíticos para comprender mejor el camino para la toma de decisiones. En esta iniciativa, Lloyd Shapley definió un valor para los juegos de coalición ${ }^{16}$ e inició, junto a D.B. Gillies, la Teoría de los Juegos Estocásticos ${ }^{17}$ y más adelante, junto a Jhon Milnor, desarrolló los primeros modelos de juego con un número infinito de participantes. ${ }^{18}$ Harold Kuhn, por su parte, reformuló el modelo e introdujo el concepto de estrategias de comportamiento. ${ }^{19}$ Luego, John Nash sentó las bases de la Teoría Cooperativa de la Negociación, proponiendo el equilibrio (que luego se denominó) de Nash. ${ }^{20}$ Mientras tanto, A. W. Tucker ${ }^{21}$ inventó el "dilema del prisionero", que es un ejemplo de la interacción entre la competencia y la cooperación ${ }^{22}$ el cual resulta típico de la teoría de los juegos y es, junto a la regla del razonamiento hacia atrás de Dixit y Nalebuff ${ }^{23}$ de especial interés para el análisis que se esboza en este trabajo.

En este orden de ideas, la competencia y la cooperación son igualmente importantes, en la medida que se parte de que la estrategia implica alcanzar el máximo beneficio posible, tomando en cuenta todos los factores que pueden afectar la decisión. Al respecto, señalan Dixit y Nalebuff:

\begin{abstract}
"Pensar estratégicamente es el arte de superar a un adversario a sabiendas de que el adversario está intentando hacer lo mismo con uno [...] también es el arte de encontrar modos de cooperar, incluso cuando los demás actúan movidos por el egoísmo y no por la benevolencia. Es el arte de convencer a los demás, e incluso a nosotros mismos, de que hagan lo que decimos. Es el arte de interpretar y de revelar información. Es el arte de interpretar y de revelar información. Es el arte de ponerse en el lugar de los demás con el fin de predecir lo que harán y de influir en ello". ${ }^{24}$
\end{abstract}

El dilema del prisionero plantea una situación en la que dos personas (desconocidas) acusadas de un mismo delito deciden confesar; la versión que dan a las autoridades no es coincidente. En esta situación, el equilibrio (de Nash), opera cuando el estado de ninguna de ellas puede empeorar. En este escenario, cada uno de los participantes tiene un incentivo personal para tomar una decisión: confesar lo sucedido, bajo la creencia de que el otro lo va a contar primero. El resultado es

\footnotetext{
${ }^{16}$ SHAPLEY, Lloyd, "Stochastic Games", Proceedings of the National Academy of Sciences of the United States of America, vol. 39, n 10 (1953), pp. 1095- 1100.

${ }^{17}$ GILLIES, Donald, "Solutions to general non-zero-sum games", en: TUCKER, Albert; LUCE, Robert, Contributions to the Theory of Games IV, Annals of Mathematics Studies 40, Princeton: Princeton University Press, 1959, pp. 47-85.

${ }^{18}$ MILNOR, John; SHAPLEY, Lloyd, "On Games of Survival", en: DRESHER, Melvin, TUCKER, Albert; WOLFE, Philip (Eds.), Contributions to the Theory of Games, Vol. III, Annals of Mathematical Studies 39, Princeton: Princeton University Press, 1957, pp. 15-45.

${ }^{19}$ KUHN, Harold, "Game Theory and Models of Negotiation", The Journal of Conflict Resolution, vol. 6, $\mathrm{n}^{\circ} 1$ (1962), pp. 1-4, p. 2.

${ }^{20}$ NASH, John, "The Bargaining Problem", Econometrica, Econometric Society, vol. 18, n 2 (1950), pp. 155-162, p. 157.

${ }^{21}$ KUHN, Harold; TUCKER, Albert, Contributions to the theory of games, Princeton: Princeton University Press, 1953.

${ }^{22}$ KUHN, Harold, "Introduction", en: VON NEUMAN, John; MORGENSTERN, Oskar, Theory of Games and Economic Behavior, 60th Anniversary Commemorative Edition VII-XIV. Princeton: Princeton University Press, 2007.

${ }^{23}$ DIXIT / NALEBUFF, El arte, cit. nota ${ }^{\circ} 9$.

${ }^{24}$ DIXIT / NALEBUFF, El arte, cit. nota n ${ }^{\circ}$ 9, p. 12.
} 
negativo, en la medida que cada uno actúa en favor de sus intereses personales. El dilema se centra en "cómo evitar un resultado en el que todo el mundo pierde o cómo lograr un resultado en que todo el mundo gana". ${ }^{25}$ Este dilema se resuelve cuando existe una estrategia dominante que resulta de analizar las decisiones que adoptan los jugadores, teniendo en cuenta las acciones de los demás.

Competencia y cooperación son igualmente importantes puesto que la estrategia implica alcanzar el máximo beneficio posible, al considerar todos los factores que pueden afectar la decisión. Por ello, "pensar estratégicamente es el arte de superar a un adversario a sabiendas de que el adversario está intentando hacer lo mismo con uno". ${ }^{26}$ En el dilema del prisionero, la interacción de los participantes es "simultánea"; es decir, cuando estos actúan sin saber exactamente lo que están pensando o haciendo los demás. ${ }^{27}$ Pero ¿qué pasa cuando los jugadores actúan de forma “consecutiva"? De acuerdo con Dixit y Nalebuff, la estrategia en estos casos implica secuencias más largas, decisiones con varias opciones para cada una de las jugadas. De ahí que, la regla fundamental es que el jugador "prevea el resultado de sus decisiones iniciales y utilice esta información para calcular su mejor opción". ${ }^{28}$

\section{El Utilitarismo Clásico y la Teoría Económica del Crimen de Gary Becker}

En la segunda mitad del siglo XX, Gary Becker ${ }^{29}$ revivió un debate suscitado en la economía clásica de finales de siglo XVIII, cuando algunos pensadores como Cesare Beccaria ${ }^{30}$ (1764) y Jeremy Bentham ${ }^{31}(1780)$, prestaron especial atención a la explicación del crimen desde una perspectiva económica racional, formulando reglas óptimas para castigar la conducta delictiva, a partir del principio de utilidad. Para Beccaria, la finalidad de la pena tiene objetivos ejemplificantes y no coercitivos. A través de la persuasión, las personas evitan cometer los delitos, al mismo tiempo que la educación constituye el medio más seguro, pero difícil, para reducir el crimen. Este planteamiento se resume en 12 principios, que son la esencia del "mercado del crimen", y que justifican por qué existe un desequilibrio entre los actos punitivos y la desaparición del delito. ${ }^{32}$

Por su parte, Jeremy Bentham, centró su atención en el comportamiento racional de las personas, llegando a pensar que estas, actuaban como maximizadores de su propio interés. ${ }^{33}$ Por ello, el problema de la delincuencia radica en establecer una serie de costos económicos por cada delito, a partir de las dos variables constitutivas de la sanción impuesta: la severidad del castigo y la probabilidad de la ley sea infringida.

\footnotetext{
${ }^{25}$ DIXIT / NALEBUFF, El arte, cit. nota ${ }^{\circ} 9$, p. 12.

${ }^{26}$ DIXIT / NALEBUFF, El arte, cit. nota ${ }^{\circ}$ 9, p. 12.

${ }^{27}$ DIXIT / NALEBUFF, El arte, cit. nota $\mathrm{n}^{\circ} 9$, p. 56.

${ }^{28}$ DIXIT / NALEBUFF, El arte, cit. nota n ${ }^{\circ} 9$, p. 58.

${ }^{29}$ BECKER, "Crime", cit. nota ${ }^{\circ} 1$, p. 2.

${ }^{30}$ BECCARIA, Cesare, De los delitos y de las penas, México: Fondo de Cultura Económica, 2011.

${ }^{31}$ BENTHAM, Jeremy, An Introduction to the Principles of Morals an Legislation, Ontario: Batoche Books, 2000.

${ }^{32}$ BECCARIA, De los delitos, cit. nota $\mathrm{n}^{\circ} 30$, pp. 25-27.

${ }^{33}$ BENTHAM, An Introduction, cit. nota $\mathrm{n}^{\circ} 31$.
} 


\title{
Polít. Crim. Vol. 14, No 28 (Diciembre 2019), Art. 9, pp. 365-384. [http://politcrim.com/wp-content/uploads/2019/12/Vol14N28A9.pdf]
}

Ambas teorías son retomadas por Becker en Crime and Punishment: An Economic Approach, donde plantea como elementos de análisis: la medida de la pena y su efecto disuasorio y luego el grado de impunidad tolerado. ${ }^{34}$ En este orden, considera la racionalidad para la maximización de la utilidad como estrategia de comportamiento, ${ }^{35}$ donde la cantidad óptima de aplicación depende, entre otras, de la diferencia entre penas y del costo de judicializar, de lo cual corresponde las respuestas del agente. $\mathrm{Al}$ respecto, el autor señala:

\begin{abstract}
"Se demuestra que la cantidad óptima de aplicación depende, entre otras cosas, del costo de atrapar y condenar a los infractores, de la naturaleza de los castigos -por ejemplo, si son multas o penas de cárcel- y de las respuestas de los infractores a los cambios en la aplicación [...] Se sugiere, por ejemplo, que una teoría útil de la conducta criminal puede prescindir de teorías especiales de la anomia, de las inadecuaciones psicológicas o de la herencia de rasgos especiales, simplemente extendiendo el análisis habitual del economista de la teoría de la elección". ${ }^{36}$
\end{abstract}

Luego, Becker divide su análisis sobre la economía del delito en "dos extremos: el estudio de la decisión de delinquir y el de la eficiencia en la asignación de recursos en la prevención del delito". ${ }^{37}$ En el primer extremo, se explicita la influencia de Bentham, dado que el crimen es una industria importante, debido a los valores económicos que reporta en términos de costos y beneficios. Por ello, este es un enfoque racional por el que un sujeto comete un delito solo cuando la utilidad esperada supera la que obtendría en otras actividades lícitas. ${ }^{38}$ En este contexto, la elección de delinquir, depende de los beneficios obtenidos de las actividades legales versus las ilegales que se ejerzan. De esta forma, si los beneficios de las actividades ilegales son superiores a la de las legales, aun teniendo en cuenta la probabilidad de captura y condena, así como la severidad del castigo, podrían provocar que la conducta delictiva se imponga en algunos casos. ${ }^{39}$

Esta premisa, es corroborada por Becker a partir de los estudios empíricos sobre criminología que demostraron un aumento per cápita del delito desde principios de la década de 1930, donde la disuasión se centra en la condena y su cumplimiento efectivo. ${ }^{40}$ De esta forma, la preferencia de los delincuentes por el riesgo de condena propicia la existencia de un mercado del delito. Así, delinquir involucra elecciones individuales estratégicas y racionales cuyo objetivo es maximizar una función de utilidad esperada teniendo en cuenta la eficiencia del marco regulatorio o justicia para desincentivar dichas actividades dado que son socialmente costosas e indeseables. ${ }^{41}$

\footnotetext{
${ }^{34}$ BECKER, "Crime", cit. nota n ${ }^{\circ} 1$, p. 2.

${ }^{35}$ BECKER, Gary, "Nobel Lecture: The Economic Way of Looking at Behavior", Journal of Political Economy, vol. 101, no 3 (1993), pp. 385-409.

${ }^{36}$ BECKER, "Crime", cit. nota n ${ }^{\circ}$ 1, p. 2.

${ }^{37}$ ORTIZ, Iñigo, "Análisis económico y delito: Lo que hay y lo que puede haber", Economía Industrial, no 398 (2015), pp. 55-64, p. 56.

${ }^{38}$ BECKER, "Crime", cit. nota n ${ }^{\circ} 1$.

${ }^{39}$ CIOCCHINI, Francisco, "El crimen y el castigo", Valores en la Sociedad Industrial, vol. 12, no 29 (1994), pp. 45 52.

${ }^{40}$ BECKER, "Crime", cit. nota ${ }^{\circ}$ 1, pp. 2-5.

${ }^{41}$ BURBANO, Enrique, "Análisis de crimen y castigo: el caso de las "parainstituciones" de invasión en Cali", Ecos de Economía 18, no 38 (2014), pp. 93-133.
} 


\section{PONCE, Ana; PIEDRAHITA, Pedro; VILLAGÓMEZ, Richard "Toma de decisiones y responsabilidad penal frente al lavado de activos en Ecuador".}

Desde otra perspectiva, tanto Durkheim como Foucault ${ }^{42}$ señalan que la pena es un elemento central para la conformación y reproducción del orden social al constituirse en un medio de interiorización de regulaciones normativas que someten a los sujetos al ordenamiento social. No obstante, para Durkheim la pena tiene una importancia sociológica excepcional porque se remite a valores nucleares del grupo y se diferencia de otras formas de castigo. ${ }^{43}$ En tanto que, para Foucault la pena es equiparable a las demás formas de sanción presentes a lo largo del cuerpo social ya sea que se trate de castigos escolares, policiales, disciplinarios, entre otros. ${ }^{44}$ De este modo, para Durkheim toda sociedad tiene un centro (núcleo); mientras que, para Foucault, la sociedad es una composición de redes que producen efectos de conglomerado, aunque la modernidad se caracteriza por la pérdida del centro que es propio de las sociedades tradicionales. Por eso, cada dispositivo disciplinario reproduce un mecanismo penal, que funciona según procedimientos generales idénticos a los de la prisión. ${ }^{45}$ En el ámbito de la ejecución penal, el aporte de Bentham relativo al panóptico es más que una idea arquitectónica, porque es la materialización coherente de un modelo moral sobre la sociedad que está abocado a limitar el alcance de los derechos humanos, apuntando a su instrumentalización y relativización histórica o cultural. ${ }^{46}$ De esta manera, Bentham se enfoca en la asignación de recursos estatales para la aplicación (al por mayor) de la pena a través de un modelo penitenciario en que se asignan pocos recursos para masificar el control de la ejecución punitiva.

Al regresar sobre Becker en relación con la prevención del delito su planteamiento es cercano a Beccaria, quien sostuvo que el recrudecimiento de la punición no disminuye necesariamente la ocurrencia delictual. Por lo tanto, el costo social de este fenómeno crece y el Estado debe asignar recursos para el cumplimiento de la condena, considerándose la asignación de recursos por cada condenado en relación con la longitud de la sentencia. ${ }^{47}$ Becker en esencia no desestima la funcionalidad de la pena privativa de libertad en delitos graves, sin embargo su predilección por la multa es evidente, por lo que existen dos formas diversas de medir el costo del crimen, la única diferencia se encuentra en la unidad que la representa ya sea tiempo y/o dinero. Así, las multas son medidas en unidades monetarias y la cárcel en unidades de tiempo.

Para matizar, Becker habla del óptimo social para encontrar una equivalencia en el poder disuasorio de las distintas sanciones. ${ }^{48}$ Empero, la crítica a este postulado radica en que el recrudecimiento de la pena privativa de libertad obligará a que la pena pecuniaria (equivalente) sea muy elevada, y en ocasiones imposible para el condenado quien no se disuade por exceder su capacidad económica. Por ello, la sanción más eficiente es una pena muy grave con una probabilidad de imposición muy baja. ${ }^{49}$ Así, la probabilidad de condena supone para el Estado un costo mayor al beneficio esperado. Por tanto, el efecto disuasorio del castigo será mayor a la

\footnotetext{
${ }^{42}$ TONKONOFF, Sergio, "Las funciones sociales del crimen y el castigo. Una comparación entre las perspectivas de Dürkheim y Foucault", Sociológica, vol. 27, no 77 (2012), pp. 109-142.

${ }^{43}$ DURKHEIM, Émile, The rules of sociological method, New York: The Free Press, 1982, pp. 50-58

${ }^{44}$ FOUCAULT, Michel, La verdad y las formas jurídicas, Barcelona: Gedisa, 1996, pp. 39-51

${ }^{45}$ TONKONOFF, "Las funciones sociales", cit. nota ${ }^{\circ} 42$.

${ }^{46}$ BEYTÍA, Pablo, "El panóptico de Bentham y la instrumentalización de los derechos humanos", Universitas Philosophica, vol. 68, no 34 (2017), pp. 173-196, p. 193.

${ }^{47}$ CIOCCHINI, "El crimen", cit. nota ${ }^{\circ} 39$.

${ }^{48}$ BECKER, "Crime", cit. nota ${ }^{\circ} 1$.

${ }^{49}$ ORTIZ, “Análisis", cit. nota n 37.
} 


\section{Polít. Crim. Vol. 14, № 28 (Diciembre 2019), Art. 9, pp. 365-384. [http://politcrim.com/wp-content/uploads/2019/12/Vol14N28A9.pdf]}

perdida social, toda vez que la violación de las leyes lleva a la destrucción de cualquier sistema jurídico y acarrea resultados perjudiciales para los miembros de la comunidad. ${ }^{50}$

En este sentido, la teoría de la justicia de Rawls enfatiza sobre la necesidad de garantizar las condiciones para que la estructura social, económica y política, posibilite y promueva una justa distribución de las bases sociales del auto respeto. ${ }^{51}$ De otro lado, el utilitarismo no ofrece estas garantías mínimas porque tiene una visión muy estrecha de la conducta humana racional y porque contraviene cuestiones sustantivas como la idea de persona moral, de modo que las demandas de las personas no son consideradas de modo equitativo. ${ }^{52}$

La noción de utilidad, desde los neoclásicos y los economistas del siglo $\mathrm{XX}$, se vincula principalmente a la teoría de la decisión, considerándose que lo fundamental no es la discusión de si existe una función de utilidad, sino cómo se llega a ella a partir de unos objetivos propuestos dentro de un contexto cambiante. Éste, supone un nivel de riesgo a evaluarse por las personas, empresas y economías en función de unos resultados que deben ser medibles ya sea de modo cualitativo (subjetivo) o cuantitativo (objetivo), y que expresan el grado de utilidad alcanzado al final de un proceso de producción en que se debe privilegiar al individuo. Todo esto pese a que se le exige productividad y competitividad, sometiéndolo a explotación e inequidad con prácticas propias de la acumulación originaria del capital que han llevado a condiciones de pauperización de la mayor parte de la población. ${ }^{53}$

\section{El Lavado de Activos en Ecuador}

El lavado de activos es un fenómeno global cada vez más creciente donde las empresas legalmente constituidas en muchas ocasiones son instrumentalizadas para ejecutar un conjunto de acciones que pretenden dar apariencia legal a recursos provenientes de actividades ilícitas. Por tanto, el objeto del lavado es dar ropaje de licitud al mayor monto de recursos derivados de estas actividades. ${ }^{54}$ Esta actividad criminal es la que da sentido al crimen organizado transnacional y además establece una dependencia intrínseca de la capacidad del comercio exterior de los Estados para generar traslados de fondos ilícitos hacia y desde su territorio.

El objetivo principal de las organizaciones criminales que utilizan esta dinámica es ocultar la fuente de los fondos ilícitos absorbiendo los fondos de nuevo a la economía social. Al respecto, un estudio de 2012 sobre China, publicado en The Economist, señaló que el desplazamiento de fondos ilícitos procedentes de un paraíso fiscal como las Islas Vírgenes Británicas podría ser una forma elaborada de blanqueo de dinero basado en el comercio. ${ }^{55}$ Un informe posterior del Grupo

\footnotetext{
${ }^{50}$ MAGOJA, Eduardo, “¿Obedecer las leyes?: utilitarismo, retórica forense y autoridad en el Critón de Platón (50a650b5)”, Tópicos, Revista de Filosofía, no 53 (2017), pp. 411- 434, p. 412.

${ }^{51}$ RAWLS, John, "Justice as Fairness", Philosophical Review, vol. 67, n 2 (1958), pp. 164-169.

${ }^{52}$ AGUAYO, Pablo, "La crítica de Rawls al utilitarismo a la luz de las nociones de autorrespeto y reconocimiento recíproco", Revista de Filosofía, vol. 7, no 1 (2016), pp. 129-150, p. 147.

${ }^{53}$ MAYORGA, José, "La visión global de la utilidad", Criterio Libre, vol. 8, nº 13 (2010), pp. 173-206.

${ }^{54}$ CONDE, María, "Unidad Antilavado de Activos, FGE", Perfil Criminológico, $\mathrm{n}^{\circ} 14$ (2015), pp. 10-11. ENRÍQUEZ-BERMEO, Francisco, "Ecuador en el circuito de lavado de activos", Perfil Criminológico, no 14 (2015), pp. 3-5.

${ }_{55}$ KAR, Dev; SPANJERS, Joseph, Illicit Financial Flows from Developing Countries: 2004-2013, Washington: Global Financial Integrity, 2015, p. 17.
} 
de Acción Financiera (GAFI) en 2012 concluyó que "el rápido crecimiento de la economía mundial ha hecho del comercio internacional una vía cada vez más atractiva para mover los fondos ilícitos a través de transacciones financieras asociadas al comercio de bienes y servicios". ${ }^{56}$

En esta línea, Castells señala que "el blanqueo de dinero es la matriz del crimen global y su punto de conexión más directo con el capitalismo global" ${ }^{, 57}$ y además enfatiza en sus tres niveles de desarrollo ya identificados por el GAFI: primero, la colocación del dinero en efectivo a través de bancos y otras instituciones en el sistema financieros en países con bajo control como Panamá, Islas Caimán, Las Bahamas, St. Martens, Vanuatu, Luxemburgo y Austria; por lo general las transacciones están reguladas en USD 10.000 dólares, por lo que las redes criminales hacen numerosas transacciones de USD 9.999 las cuales en apariencia son legales. Segundo, la separación de la fuente de los fondos a través de transferencias electrónicas en tiempo real, esto para evitar la detección por auditorías; lo más complejo de este eslabón son también las operaciones en efectivo, en diversas monedas o valores y la utilización de los dineros ilegales como prendas de garantía en préstamos de fondos legales. Esto se evidencia en las mínimas incautaciones de fondos ilegales que se realizan en países capitalistas. Y, tercero, la inclusión de los capitales ya blanqueados a la economía legal, bajo figuras de compra de propiedades, artículos suntuosos, carros lujosos, etc., que posteriormente vuelven se unen al "torbellino de los flujos financieros globales" ${ }^{58}$ De esta forma se da la configuración de una compleja red de trabajo que garantiza la inclusión de gran cantidad de dinero al sistema financiero global.

Frente a esta situación, el Ecuador fortaleció su marco normativo interno al crear el COIP, que tipifica el lavado de activos en el artículo 317, creando una escala penal diferenciada en la que se considera la dosificación punitiva por el monto de los activos lavados, en consonancia con el criterio de dosimetría reconocido en el artículo 75 de la Constitución de la República del Ecuador (CRE), por lo que la pena debe ser dosificada en función del daño que representa el delito. De esta forma, la medida de la pena, tanto privativa de libertad como pecuniaria, es directamente proporcional al daño que produce el delito, conforme la siguiente escala:

"1. Con pena privativa de libertad de uno a tres años cuando el monto de los activos objeto del delito sea inferior a cien salarios básicos unificados del trabajador en general.

2. Con pena privativa de libertad de cinco a siete años cuando la comisión del delito no presuponga la asociación para delinquir. Con pena privativa de libertad de siete a diez años, en los siguientes casos:

a) Cuando el monto de los activos objeto del delito sea igual o superior a cien salarios básicos unificados del trabajador en general.

b) Si la comisión del delito presuponga la asociación para delinquir, sin servirse de la constitución de sociedades o empresas, o de la utilización de las que se encuentren legalmente constituidas.

c) Cuando el delito sea cometido utilizando instituciones del sistema financiero o de seguros; instituciones públicas o dignidades; o, en el desempeño de cargos directivos, funciones o empleos en dichos sistemas.

\footnotetext{
${ }^{56}$ KAR / SPANJERS, Illicit Financial, cit. nota $\mathrm{n}^{\mathrm{o}}$ 55, p. 17.

${ }^{57}$ CASTELLS, La Era, cit. nota n ${ }^{\circ} 3$, pp. 212-213.

${ }^{58}$ CASTELLS, La Era, cit. nota n ${ }^{\circ}$, p. 213.
} 


\section{Polít. Crim. Vol. 14, № 28 (Diciembre 2019), Art. 9, pp. 365-384. [http://politcrim.com/wp-content/uploads/2019/12/Vol14N28A9.pdf]}

3. Con pena privativa de libertad de diez a trece años, en los siguientes casos:

a) Cuando el monto de los activos objeto del delito supere los doscientos salarios básicos unificados del trabajador en general.

b) Cuando la comisión del delito presupone la asociación para delinquir a través de la constitución de sociedades o empresas, o de la utilización de las que se encuentren legalmente constituidas.

c) Cuando el delito ha sido cometido utilizando instituciones públicas, o dignidades, cargos o empleos públicos.

En los casos antes mencionados, el lavado de activos también se sanciona con una multa equivalente al duplo del monto de los activos objeto del delito, comiso de conformidad con lo previsto en este Código, disolución y liquidación de la persona jurídica creada para la comisión del delito, de ser el caso". 59

$\mathrm{Al}$ analizarse los elementos constitutivos del tipo penal, la principal innovación que se advierte es la ampliación de la responsabilidad penal hacia las personas jurídicas, dado que tradicionalmente esta conducta era solo reprochable a personas naturales no calificadas quienes tenían la calidad de sujeto activo. De este modo, actualmente se pueden impulsar procesos penales por lavado de activos tanto en contra de personas naturales como jurídicas, de lo cual la toma de decisiones al momento de delinquir no solo afecta a los directivos de una empresa sino también a la empresa misma, con diversa punición ya sea que se trate de uno u otro, enfatizándose para los primeros la pena privativa de libertad, en tanto que para la persona jurídica el castigo se enfoca en el cese de sus actividades económicas y la pena pecuniaria.

La lógica de estas medidas jurídicas se entiende a partir de la apropiación de sistemas antilavado y sistemas de administración de riesgos del lavado de activos, asuntos que en la mayor parte de los marcos legales de los estados occidentales deben implementarse en articulación con las empresas, bancos y sector financiero. La legislación ecuatoriana va en la dirección de que para combatir este delito es necesaria el trabajo conjunto con la banca y el sistema financiero, pues es este el sector que conoce de primera mano las sospechas sobre operaciones: "el mejor aliado del Estado en la lucha contra la delincuencia organizada es la banca, puesto que su posición en la sociedad le permite el conocimiento de información a la que normalmente las autoridades no están en condiciones de acceder, o no tienen la capacidad de procesar" ${ }^{60}$ En este contexto, el avance normativo del Ecuador permite conocer no solo los casos de transacciones sospechosas por personas naturales y jurídicas.

Dicho lo anterior, para ejemplificar el análisis costo beneficio en relación con el lavado de activos, se toma un caso resuelto por la Corte Nacional de Justicia, mediante sentencia de 1 de junio de 2017, en la que se declaró la responsabilidad del acusado a quien se le impone en calidad de autor, la pena privativa de libertad, pecuniaria y otras. Así, entre la amenaza de sanción (prevista en la norma) versus la sanción impuesta en sentencia, se establecen los resultados que derivan de la toma de decisiones en relación con el delito de lavado de activos. Para la persona que debe tomar la decisión, debe precisar el beneficio económico de resultar favorecido por el ingreso a sus cuentas de 816,237.27 USD, producto del blanqueamiento de fondos ilegales a través de una empresa legalmente constituida. En este caso, el beneficio es netamente monetario, y la empresa a través de la cual se comete el ilícito, es netamente

\footnotetext{
${ }^{59}$ CÓDIGO ORGÁNICO INTEGRAL PENAL (COIP), Asamblea Nacional del Ecuador, 2014, artículo 317.

${ }^{60}$ SINTURA / MARTÍNEZ / QUINTANA, Sistemas de prevención, cit. nota ${ }^{\circ}$ 4, p. 8.
} 
instrumental para este fin. Por su parte, el costo que implica la decisión del agente, trae la amenaza de pena: (1) privativa de libertad de siete a diez años, puesto que los ingresos superan los cien salarios básicos unificados (SBU); (2) multa por 1'632,474.54 USD, correspondiente al duplo del monto de los activos lavados; (3) comiso especial de los bienes de propiedad del acusado; (4) otros.

El siguiente esquema de árbol de decisiones permite ilustrar las opciones racionales que tiene la persona en el umbral de toma de decisión:

\section{Gráfico 1. Árbol de decisión sobre lavado de activos.}

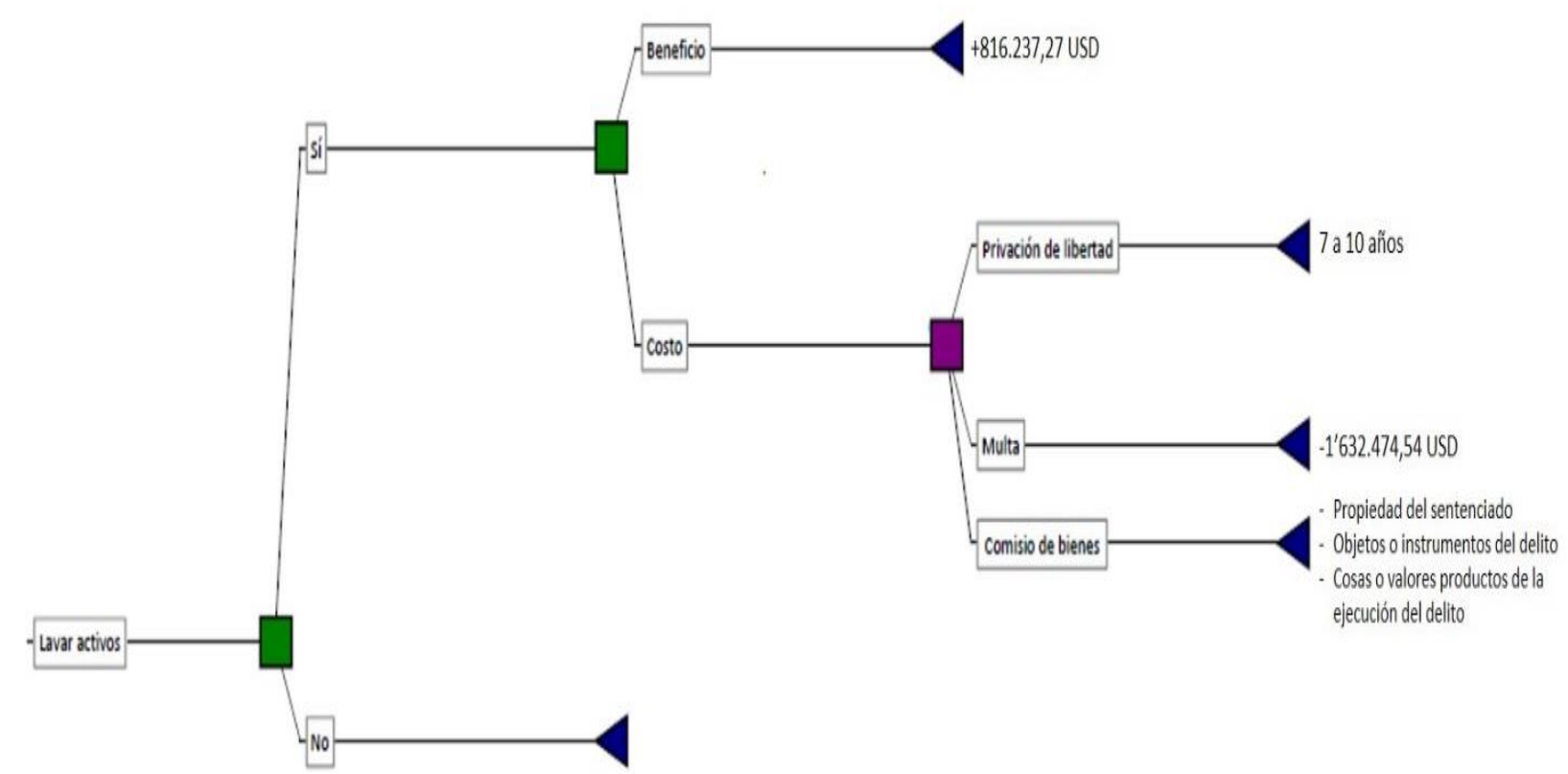

Nota: adaptado del artículo 317, CÓDIGO ORGÁNICO INTEGRAL PENAL (COIP), Asamblea Nacional del Ecuador, 2014.

Se evidencia entonces en el esquema de árbol que a partir de la decisión racional de participar en un proceso de lavado de activos puede generar altos réditos económicos. Sin embargo, aparecen cuestiones fundamental que podría incidir en la toma de decisión ¿sabe el sujeto los costos totales del ilícito? Es decir, ¿existe un pleno conocimiento de las sanciones más allá de la privación de la libertad?, ¿la persona natural o jurídica sabe los costos de la multa y comiso de bienes?

\section{Factores determinantes para la toma de decisión}

La economía y el derecho coinciden en aceptar por igual las racionalidades instrumentales y valorativas, asociadas a los conceptos de homo economicus y homo sociologicus de Max 


\section{Polít. Crim. Vol. 14, No 28 (Diciembre 2019), Art. 9, pp. 365-384. [http://politcrim.com/wp-content/uploads/2019/12/Vol14N28A9.pdf]}

Weber. ${ }^{61}$ En esta línea de pensamiento, Robbins sostiene que "las leyes económicas no pueden limitarse a describir los movimientos de escalas relativas, y la causación económica sólo abarca la amplitud de sus supuestos originales". ${ }^{62}$ Esto en relación con el marco social implica que, las pautas de convivencia han sido producidas como mecanismos de coordinación o solución de problemas sociales en que también se incluyen los delitos. Desde esta perspectiva, la teoría del juego, también podrían considerarse parte de las normas sociales, dado que no es meramente instrumental, como sostiene el utilitarismo clásico, sino que corresponde a valores jurídicos, políticos, sociológicos, psicológicos, religiosos y económicos, tal y como lo plantean Becker, ${ }^{63}$ Ortiz $^{64}$ y Ciocchini. ${ }^{65}$

Frente a las normas penales, las personas (naturales/jurídicas) pueden tomar la decisión (racional) de delinquir o no, dependiendo de la relación costo-beneficio que establezcan para ello. Así, la decisión se basa en un examen racional, de orden económico, que no necesariamente involucra un nivel ético, que introduce valores morales, sociales, religiosos, etc. ${ }^{66}$ Esto pese a que Robbins y Judge advierten que la dimensión ética es importante en las decisiones organizacionales, debido al exhaustivo examen por el que pasan los responsables de las empresas en relación con sus actuaciones. ${ }^{67}$ Por tanto, el escrutinio no solo es jurídico o financiero (responsabilidad empresarial), puesto que involucra otros factores de orden social. ${ }^{68}$ Por ello, al tomar decisiones sobre el lavado de activos en las empresas, cobra importancia estos factores que superan la visión de Becker, que se focaliza de modo exclusivo en la relación costo-beneficio.

En Ecuador, al realizarse el análisis económico del lavado de activos, se parte de la consideración de costo social por el que este ilícito ha aumentado un promedio anual de 1,151 millones de dólares durante el periodo 2002-2011. ${ }^{69}$ Luego, el análisis se amplía al beneficio utilitario que deja el ilícito para quienes lo perpetran. De esta forma, el análisis, pasa por un examen de varios factores en que se incluye: el contenido de las normas penales y de la medida sanción (privativa de la libertad y pecuniaria) que se impone en sentencias proferidas por los organismos judiciales.

$\mathrm{Al}$ revisar el marco normativo del lavado de activos y el conjunto de la escala penal, hay penas privativas de la libertad, pecuniarias y otras, existiendo la posibilidad de perseguir a personas naturales y jurídicas en un solo proceso penal, ${ }^{70}$ lo que brinda sinergia a la represión estatal. Desde la perspectiva de Becker, esto, prima faccie, dota al corpus juris ecuatoriano de elementos disuasorios potentes para la represión, desalentando la toma de decisión sobre delinquir o no, de

\footnotetext{
${ }^{61}$ PÉREZ, Juan, "Valores, normas y teoría económica: Algunas consideraciones”, El trimestre económico, vol 67, $\mathrm{n}^{\circ} 268$ (2000), pp. 579-616.

${ }^{62}$ ROBBINS, Lionel, Ensayo sobre la naturaleza y significación de la ciencia económica, México: Fondo de Cultura Económica, 1980, p. 95.

${ }^{63}$ BECKER, "Crime", cit. nota ${ }^{\circ} 1$.

${ }^{64}$ ORTIZ, "Análisis", cit. nota n 37.

${ }^{65}$ CIOCCHINI, "El crimen", cit. nota ${ }^{\circ} 39$.

${ }^{66}$ PÉREZ, "Valores", cit. nota n ${ }^{\circ} 61$.

${ }^{67}$ ROBBINS / JUDGE, Organizational, cit. nota n ${ }^{\circ} 11$, pp. 103-106.

${ }^{68}$ ROBBINS / JUDGE, Organizational, cit. nota ${ }^{\circ} 11$.

${ }^{69}$ FIERRO, Luis, "Flujos financieros ilícitos en el Ecuador se estiman en \$ 1.150 millones", Gestión, no 238 (2016), pp. 28-32.

${ }^{70}$ CÓDIGO ORGÁNICO INTEGRAL PENAL (COIP), cit. nota nº 59, artículo 50.
} 


\section{PONCE, Ana; PIEDRAHITA, Pedro; VILLAGÓMEZ, Richard "Toma de decisiones y responsabilidad penal frente al lavado de activos en Ecuador".}

lo cual la disyuntiva radica entre cometer el delito y no ser sancionado, o cometerlo y ser sancionado.

Desde el marco de la punición, el lavado de activos abarca no solo la pena pecuniaria, que sería el mejor escenario posible, puesto que la unidad de medida de la pena (dinero) no cambia respecto a la unidad de medida que motiva el ilícito (dinero). No obstante, la pena también es privativa de la libertad, y se expresa a través de la unidad de medida tiempo, punición que es propia de la responsabilidad de las personas naturales, a diferencia de la punición en personas jurídicas que se centra en lo pecuniaria. Así, mientras el énfasis en la represión de las personas naturales se expresa en unidades de tiempo, en las personas jurídicas se expresa en unidades monetarias (dinero).

Complementario al análisis costo beneficio que realiza el agente del delito - ya sea persona natural o jurídica - también existe desde el Estado un análisis de coste social que se centra en la asignación de recursos principalmente para reprimir el delito una vez ocurrido, aunque no se excluye la posibilidad de análisis en el ámbito de la prevención. Sobre el coste de represión, Beccaria proponía en 1764 dos dimensiones relacionadas con: a. los costos externos, centrados en la víctima, y, b. los sociales, centrados en el contexto de afectación. ${ }^{71}$ En este sentido, el daño que ocasiona el lavado de activos, desde el discurso penal, no se centra en un bien jurídico individual debido a que no existe una víctima tangible que origine costos externos, sino que tal afectación es a un bien jurídico colectivo, que provoca costos sociales en detrimento del bien común.

Precisados los costes del delito desde el agente (persona natural/jurídica) y el Estado, debe considerarse que conforme el COIP, la toma de decisión pasa por un ejercicio en que se pondera los costos del ilícito, en relación con las medidas disuasorias (en tiempo y dinero), como se explica en la tabla 1.

\footnotetext{
${ }^{71}$ JAITMAN, Laura, "Introducción: los costos del crimen en el bienestar", en: JAITMAN, Laura, Los costos del crimen y la violencia en el bienestar en América Latina y el Caribe, Washington: Banco Interamericano de Desarrollo, 2015.
} 


\section{Polít. Crim. Vol. 14, No 28 (Diciembre 2019), Art. 9, pp. 365-384. [http://politcrim.com/wp-content/uploads/2019/12/Vol14N28A9.pdf]}

Tabla 1 - Escala penal dosificada

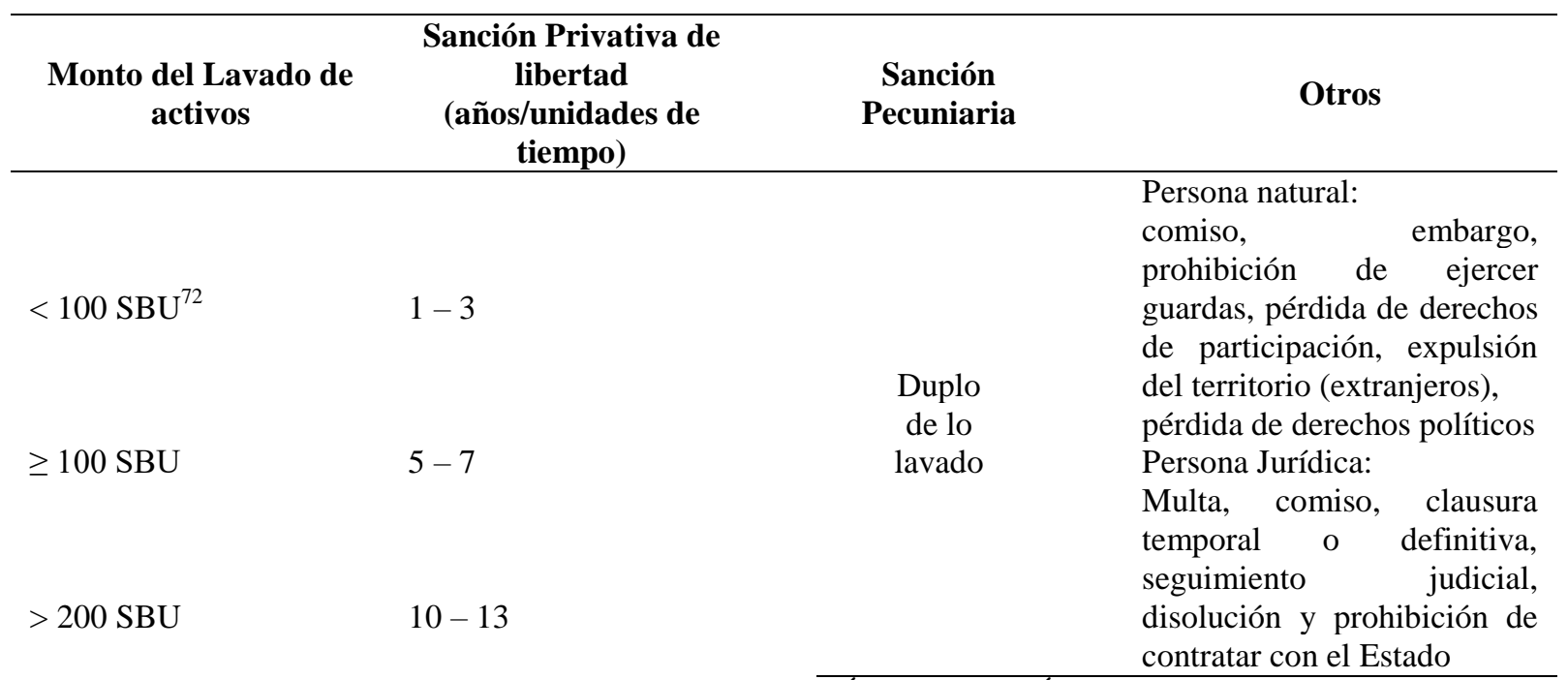

Nota. Adaptaro de los artículos 61, 64, 65, 68, 69 y 3, CÓDIGO ORGÁNICO INTEGRAL PENAL (COIP), Asamblea Nacional del Ecuador, 2014.

En referencia con lo expresado en el cuadro anterior, y atendiendo la relación costo-beneficio, determinante para la toma de decisión, vale rescatar las consideraciones de Ortiz frente a la actuación del Estado:

"Dado un determinado coste esperado/nivel de disuasión, podemos mantenerlo incrementando una de las dos magnitudes (gravedad o probabilidad) en la misma proporción en que disminuimos la otra: conforme al modelo (importante caveat), una pena de 2 años de prisión con una probabilidad de imposición del 10\% disuadirá lo mismo que una de 1 año de prisión con una probabilidad de imposición del $20 \%$ y que una de 4 años de prisión con una probabilidad de imposición del 5\%. Sin embargo, los costes de cada una de estas combinaciones de severidad y certeza son distintos".73

Para el análisis de la relación costo beneficio, se debe considerar que la actuación del sujeto activo se circunscribe a un interés o provecho propio (sea una persona natural o jurídica), de donde emana la responsabilidad según los actos ejecutados y de la instrumentalización o no de la persona jurídica para la consumación del lavado de activos. En particular, en organizaciones complejas es difícil determinar quién es el responsable de una decisión o de su ejecución, pues al tratarse de órganos colegiados y su ejecución por gerentes o representantes legales, es necesario diferenciar las motivaciones que existen entre unos y otros. Desde la óptica de la prevención del lavado de activos, hay que: a) separar la responsabilidad de las personas naturales que intervienen versus la de las personas jurídicas; y, b) objetivizar la atribución de responsabilidad, ${ }^{74}$ para lo cual deben distinguirse los actos ejecutados por las personas naturales

\footnotetext{
${ }^{72}$ Salario Básico Unificado que se indexa anualmente conforme el indicador de inflación.

${ }^{73}$ ORTIZ, “Análisis", cit. nota n 37.

${ }^{74}$ MATUS, Jean, "Informe sobre el proyecto de ley que establece la responsabilidad legal de las personas jurídicas en los delitos de lavado de activos, financiamiento del terrorismo y delitos de cohecho que indica, mensaje $\mathrm{N}^{\circ} 018$ 357', Ius et Praxis, vol. 15, no 2 (2009), pp. 285-306.
} 


\section{PONCE, Ana; PIEDRAHITA, Pedro; VILLAGÓMEZ, Richard "Toma de decisiones y responsabilidad penal frente al lavado de activos en Ecuador".}

y precisarse la instrumentalización o no de la persona jurídica para la consumación del lavado de activos.

Desde antaño, la regulación de la actividad de la empresa estuvo enmarcada dentro del derecho societario y el derecho administrativo que resultaron ineficaces para limitar la actividad de las altas jerarquías de las organizaciones. No obstante, este control se amplió hacia los linderos del Derecho Penal, creyendo que es la única forma de abordar el conflicto cuando los demás medios son ineficaces; y se ha centrado en la persuasión al redefinir los fines de la pena en términos preventivos especiales y preventivos generales. Por tanto, la finalidad preventiva de la pena se encuentra ligada al principio de culpabilidad como límite hasta dónde puede llegar esta redefinición en atención a la participación de personas naturales o jurídicas.

En este orden de ideas, se han ido ampliado los tipos penales, aunque la efectividad de la norma se plasma en la judicialización y la ulterior condena. Por ello, esta forma de intervención en torno a la actividad empresarial, debe partir de la correcta identificación del bien jurídico que se protege que, tratándose del lavado de activos, se centra en la seguridad del ordenamiento económico, para lo cual se busca a través de la norma, la paridad de los operadores del mercado, sin sacrificar las garantías, ${ }^{75}$ de lo cual también es necesaria la autorregulación , considerándose que las empresas que cumplen seriamente con sus deberes no tienen nada que temer. ${ }^{76}$

La opción político criminal por la que se inclinó Ecuador en el COIP, no se centra en la creación de nuevos tipos penales relacionados con el lavado de activos, sino que se mantiene en lo principal la descripción típica de la ley penal anterior, habiéndose introducido un criterio constitucional de dosimetría penal a partir de la medida de la dañosidad ocasionada (lesividad) en función del monto del dinero lavado. Además el sistema de pena es pendular al establecer un piso (mínimo) y un techo (máximo), a lo que se añade el análisis de circunstancias atenuantes y la concurrencia de agravantes que aumentan la sanción en un tercio por sobre el máximo de la pena. $^{77}$

Con todo, se evidencia que la toma de decisiones frente al lavado de activos cobra importancia cuando el Derecho Penal ha ampliado su efecto preventivo, incluyendo dentro de la participación la responsabilidad de las personas jurídicas en la perpetración de este delito. Por tanto, aunque inicialmente el efecto es económico, obliga a analizar al agente (persona natural o jurídica) el costo beneficio para la consumación del delito y de la represión que puede devenir de aquello, cuando la medida de la punición ha aumentado en consideración del monto del dinero lavado.

\section{Conclusiones}

Puestas a prueba los preceptos de la teoría de juegos en relación con la teoría económica del crimen de Becker, instrumentos que son básicos para analizar un caso hipotético en el que los

\footnotetext{
${ }^{75}$ FIGUEREDO, Valeria, "Macrocriminalidad económica y las 40 recomendaciones del GAFI para combatirla", Revista de Derecho, vol. 15, no 29 (2016), pp. 117-143.

${ }^{76}$ HERNÁNDEZ, Héctor, "La introducción de la responsabilidad penal de las personas jurídicas en Chile", Política Criminal: Revista Electrónica Semestral de Políticas Públicas en Materias Penales, vol. 5, nº 9 (2010), pp. 2017236.

${ }^{77}$ CÓDIGO ORGÁNICO INTEGRAL PENAL (COIP), cit. nota nº 59, artículo 44.
} 


\section{Polít. Crim. Vol. 14, No 28 (Diciembre 2019), Art. 9, pp. 365-384. [http://politcrim.com/wp-content/uploads/2019/12/Vol14N28A9.pdf]}

representantes de una empresa deben tomar la decisión sobre lavar o no activos. Dos reglas de la teoría de juegos (razonamiento hacia atrás y el dilema del prisionero) formuladas por Dixit y Nalebuff sirven para construir el árbol de decisión de las personas que deben enfrentar la encrucijada entre delinquir o no. Los planteamientos de Becker ${ }^{78}$ permiten sopesar en cada caso el costo-beneficio al momento de decidir delinquir, bajo la creencia de que el riesgo tomado puede merecer la pena impuesta o que habiendo tomado la decisión de lavar activos, la conducta quede impune al no judicializarse. ${ }^{79}$

De otra parte, desde el interés del Estado, al momento de analizarse el coste del delito, debe precisarse ya sea un enfoque ora preventivo o represivo. En general, el análisis económico del delito se centra en el aspecto represivo, cuando el lavado de activos ya ha ocurrido y por tanto existe una sentencia condenatoria, ya sea impuesta en contra de una persona natural a través de una pena privativa de libertad (pena pecuniaria y otras) o bien en contra de una persona natural en que se tiene el cierre de la actividad económica, el comiso y la pena pecuniaria. De este modo, la ejecución de la pena en tratándose de persona natural implica para el Estado un costo que va desde la adecuación del lugar de cumplimiento de la sanción y los gastos que significa dotar de Derechos Humanos en esta fase del Derecho Penal. De su lado, la perpetración del lavado de activos por persona jurídica que ha sido condenada, afecta no solo la vida de la organización sino el circuito económico de un país en atención al volumen que puede ser legalizado a través de este medio delictual, constituyendo una amenaza a la seguridad del Estado. ${ }^{80}$

Así, la determinación utilitarista del modelo de Becker y de elección racional de la teoría de juegos se cumple al analizar la posibilidad de ejecutar el delito de lavado de activos ya sea por persona natural o por persona jurídica con diversas consecuencias en el esquema de sanciones. No obstante, ambas teorías suponen retos para el análisis, pues simplifican el conjunto de variables que intervienen en la toma de decisión del agente, sin que esto sea posible, a decir de Ciocchini,${ }^{81}$ aplicarlo para explicar los aspectos más sensibles de la vida humana, dado que en el análisis económico del delito incluso debe introducirse otras variables de índole sociológica, jurídica, ética, etc., que intervienen de manera directa en la toma de la decisión individual o de la organización, de donde, la pregunta de Amartya Sen es radical al plantear: “Es la economía realmente tan hostil a la felicidad y la sociabilidad que la bonhomía debe ser despiadadamente vencida antes de estar en condiciones de considerar la economía política?". ${ }^{2}$

\footnotetext{
${ }^{78}$ BECKER, "Crime", cit. nota ${ }^{\circ} 1$.

${ }^{79}$ PULIDO, Álvaro, "El hurto de energía y cambios regulatorios en zonas de Cundinamarca: una mirada desde la economía del crimen", Equidad y Desarrollo, nº 28 (2017), pp. 227-258.

${ }^{80}$ FERRATTO, Andrés, "Crimen organizado e inteligencia estratégica: desafíos para el siglo XXI", URVIO Revista Latinoamericana de Seguridad Ciudadana, $\mathrm{n}^{\circ} 15$ (2014), pp. 55-70, p. 57.

${ }^{81}$ CIOCCHINI, "El crimen", cit. nota n 39.

${ }^{82}$ SEN, Amartya, La idea de la justicia, Madrid: Taurus, 2010, p. 299.
} 


\section{Bibliografía}

AGUAYO, Pablo, "La crítica de Rawls al utilitarismo a la luz de las nociones de autorrespeto y reconocimiento recíproco", Revista de Filosofía, vol. 7, n 1 (2016), pp. 129-150.

BECCARIA, Cesare, De los delitos y de las penas, México: Fondo de Cultura Económica, 2011.

BECKER, Gary, "Crime and Punishment: An Economic Approach", en: BECKER, Gary; LANDES, William, Essays in the Economics of Crime and Punishment, Cambridge: NBER, 1974, pp. 1-54.

BECKER, Gary, "Nobel Lecture: The Economic Way of Looking at Behavior", Journal of Political Economy, vol. 101, no 3 (1993), pp. 385-409.

BENTHAM, Jeremy, An Introduction to the Principles of Morals an Legislation, Ontario: Batoche Books, 2000.

BEYTÍA, Pablo, "El panóptico de Bentham y la instrumentalización de los derechos humanos", Universitas Philosophica, vol. 68, no 34 (2017), pp. 173-196.

BURBANO, Enrique, "Análisis de crimen y castigo: el caso de las "parainstituciones" de invasión en Cali”, Ecos de Economía 18, n 38 (2014), pp. 93-133.

CASTELLS, Manuel, La Era de la Información: economía sociedad y cultura. Vol III: Fin del Milenio, México: Siglo XII Editores, 2006.

CIOCCHINI, Francisco, "El crimen y el castigo", Valores en la Sociedad Industrial, vol. 12, no 29 (1994), pp. 45-52.

CÓDIGO ORGÁNICO INTEGRAL PENAL (COIP), Asamblea Nacional del Ecuador, 2014.

CONDE, María, "Unidad Antilavado de Activos, FGE”, Perfil Criminológico, no 14 (2015), pp. 10-11.

DIXIT, Avinash; NALEBUFF, Barry, El arte de la estrategia: la teoría de juegos, Barcelona: Antoni Bosch, 2010.

DURKHEIM, Émile, The rules of sociological method, New York: The Free Press, 1982.

ENRÍQUEZ-BERMEO, Francisco, "Ecuador en el circuito de lavado de activos", Perfil Criminológico, $\mathrm{n}^{\mathrm{o}} 14$ (2015), pp. 3-5.

FERRATTO, Andrés, "Crimen organizado e inteligencia estratégica: desafíos para el siglo XXI", URVIO - Revista Latinoamericana de Seguridad Ciudadana, no 15 (2014), pp. 55-70.

FIERRO, Luis, "Flujos financieros ilícitos en el Ecuador se estiman en \$ 1.150 millones", Gestión, no 238 (2016), pp. 28-32.

FIGUEREDO, Valeria, "Macrocriminalidad económica y las 40 recomendaciones del GAFI para combatirla", Revista de Derecho, vol. 15, no 29 (2016), pp. 117-143.

FINANCIAL ACTION TASK FORCE, "Money Laundering. Financial Action Task Force", [En línea] FATF-GAFI, (s.f.) [Citado el: 15 de Enero de 2018.] https://www.fatfgafi.org/faq/moneylaundering/.

FLACSO, "Las cifras de lavado de activos", Perfil Criminológico, n 14 (2015).

FOUCAULT, Michel, La verdad y las formas jurídicas, Barcelona: Gedisa, 1996.

GASTALDI, Carlota; URREA, Marcel; FERNÁNDEZ-DE CÓRDOBA, Pedro, "Teoría de la Decisión: contribuciones de von Neumann”, Divulgaciones Matemáticas, vol. 6, $\mathrm{n}^{\mathrm{o}} 1$ (1998), pp. 37-42.

GILLIES, Donald, "Solutions to general non-zero-sum games”, en: TUCKER, Albert; LUCE, Robert, Contributions to the Theory of Games IV, Annals of Mathematics Studies 40, Princeton: Princeton University Press, 1959, pp. 47-85. 


\section{Polít. Crim. Vol. 14, No 28 (Diciembre 2019), Art. 9, pp. 365-384. [http://politcrim.com/wp-content/uploads/2019/12/Vol14N28A9.pdf]}

HERNÁNDEZ, Héctor, "La introducción de la responsabilidad penal de las personas jurídicas en Chile", Política Criminal, vol. 5, no 9 (2010), pp. 2017-236.

JAITMAN, Laura, "Introducción: los costos del crimen en el bienestar", en: JAITMAN, Laura, Los costos del crimen y la violencia en el bienestar en América Latina y el Caribe, Washington: Banco Interamericano de Desarrollo, 2015.

KAR, Dev; SPANJERS, Joseph, Illicit Financial Flows from Developing Countries: 2004-2013, Washington: Global Financial Integrity, 2015.

KUHN, Harold, "Game Theory and Models of Negotiation", The Journal of Conflict Resolution, vol. 6, $\mathrm{n}^{\circ} 1$ (1962), pp. 1-4.

KUHN, Harold, "Introduction", en: VON NEUMAN, John; MORGENSTERN, Oskar, Theory of Games and Economic Behavior, 60th Anniversary Commemorative Edition VII-XIV. Princeton: Princeton University Press, 2007.

KUHN, Harold; TUCKER, Albert, Contributions to the theory of games, Princeton: Princeton University Press, 1953.

MAGOJA, Eduardo, ¿¿Obedecer las leyes?: utilitarismo, retórica forense y autoridad en el Critón de Platón (50a6-50b5)", Tópicos, Revista de Filosofía, no 53 (2017), pp. 411- 434.

MATUS, Jean, "Informe sobre el proyecto de ley que establece la responsabilidad legal de las personas jurídicas en los delitos de lavado de activos, financiamiento del terrorismo y delitos de cohecho que indica, mensaje N 018-357”, Ius et Praxis, vol. 15, no 2 (2009), pp. 285-306.

MAYORGA, José, "La visión global de la utilidad”, Criterio Libre, vol. 8, nº 13 (2010), pp. 173206.

MILNOR, John; SHAPLEY, Lloyd, "On Games of Survival”, en: DRESHER, Melvin, TUCKER, Albert; WOLFE, Philip (Eds.), Contributions to the Theory of Games, Vol. III, Annals of Mathematical Studies 39, Princeton: Princeton University Press, 1957, pp. 1545.

NASH, John, "The Bargaining Problem", Econometrica, Econometric Society, vol. 18, n ${ }^{\circ}$ (1950), pp. 155-162.

NEUMANN, John; MORGENSTERN Oskar, Theory of Games and Economic Behavior, Princeton: Princeton University Press, 1944.

ORTIZ, Iñigo, “Análisis económico y delito: Lo que hay y lo que puede haber", Economía Industrial, $\mathrm{n}^{\mathrm{o}} 398$ (2015), pp. 55-64.

PÉREZ, Juan, "Valores, normas y teoría económica: Algunas consideraciones", El trimestre económico, vol 67, no 268 (2000), pp. 579-616.

PIEDRAHITA, Pedro, "Las redes del crimen global y su impacto en Colombia", Analecta Política, vol. 4, nº 6 (2014), pp. 121-141.

PULIDO, Álvaro, "El hurto de energía y cambios regulatorios en zonas de Cundinamarca: una mirada desde la economía del crimen", Equidad y Desarrollo, no 28 (2017), pp. 227-258.

RAWLS, John, "Justice as Fairness", Philosophical Review, vol. 67, n² 2 (1958), pp. 164-169.

ROBBINS, Lionel, Ensayo sobre la naturaleza y significación de la ciencia económica, México: Fondo de Cultura Económica, 1980.

ROBBINS, Stephen; JUDGE, Timothy, Organizational behavior, Boston: Pearsons, 2013.

SEN, Amartya, La idea de la justicia, Madrid: Taurus, 2010.

SHAPLEY, Lloyd, "Stochastic Games", Proceedings of the National Academy of Sciences of the United States of America, vol. 39, n 10 (1953), pp. 1095- 1100. 
SINTURA, Francisco; MARTÍNEZ, Wilson; QUINTANA, Fernando, Sistemas de prevención de lavado de activos y financiación del terrorismo, Bogotá: Legis, 2014.

SPANJERS, Joseph; SALOMON, Matthew, Illicit Financial Flows to and from Developing Countries: 2005-2014, Washington: Global Financial Integrity, 2017.

TONKONOFF, Sergio, "Las funciones sociales del crimen y el castigo. Una comparación entre las perspectivas de Dürkheim y Foucault”, Sociológica, vol. 27, no 77 (2012), pp. 109142. 